\title{
A Review of Research in Manufacturing Prognostics
}

\author{
K.M. Goh ${ }^{1,2,3}$, Member of IEEE, B. Tjahjono ${ }^{2}$, T. Baines ${ }^{2}$ and S. Subramaniam ${ }^{3}$ \\ ${ }^{1}$ Singapore Institute of Manufacturing Technology (SIMTech) \\ ${ }^{2}$ Cranfield University - School of Industrial \& Manufacturing Science (SIMS) \\ ${ }^{3}$ Nanvang Technological Universitv - School of Mechanical \& Aerosbace Engineering (MAE)
}

\begin{abstract}
With the fast changing global business landscape, manufacturing companies are facing increasing challenge to reduce cost of production, increase equipment utilization and provide innovative products in order to compete with countries with low labour cost and production cost. On of the methods is zero down time. Unfortunately, the current research and industrial solution does not provide user friendly development environment to create "Adaptive microprocessor size with supercomputer performance" solution to reduce downtime. Most of the solutions are PC based computer with off the shelf research software tools which is inadequate for the space constraint manufacturing environment in developed countries. On the other hand, to develop solution for various manufacturing domain will take too much time, there is lacking tools available for rapid or adaptive way of create the solution. Therefore, this research is to understand the needs, trends, gaps of manufacturing prognostics and defines the research potential related to rapid embedded system framework for prognostics.
\end{abstract}

Keywords-maintenance, prognostics, condition based maintenance, prognostics health monitoring

\section{INTRODUCTION}

$\mathrm{D}$ EVELOPED countries is moving toward high value added and high technologies based manufacturing as it is a very important sector that contributed to employment and economic development. With the advance in technology and increasing competitiveness from some low labour cost countries, manufacturing sector in developed countries face its toughest challenge. Increasingly, these challenges depend critically on reducing production cost, increase equipment utilization and innovative products development so as to maximise its competitiveness.

Therefore, there is an urgent need to develop and provide solution that can improve manufacturing system and equipment utilization. With user friendly development environment in the embedded system, solution can be small, intelligent and could be generated by domain experts. The embedded solution for manufacturing prognostics will enable companies to achieve near zero downtime, higher productivity to keep developed countries on the competitive edge in this ever-changing economy. Hence, the research aim is to understand the needs, trends, gaps of manufacturing prognostics and defines the research potential related to rapid embedded system framework for prognostics.

1-4244-9701-0/06/\$20.00 @2006 IEEE.

\section{INDUSTRIAL PROBLEMS}

Manufacturing environment needs to be highly responsive to customer demand changes and it becomes vital for manufacturing plant to have a shorter marketing window with the competitive price and quality. Shop floor system and equipment needs to be fully utilized and optimized to zero downtime, zero setup.

Traditionally, the manufacturing plant performed the fail and fix maintenance procedures. Early detection of failures and prognostics in systems is very crucial for maintenance operations. With increasing trend towards automation in different manufacturing industries, it has become necessary that the downtime of any equipment system be reduced to minimum. Machine breakdowns are not only expensive in terms of production losses but also important in meeting production schedules. In addition, due to the fast growth of equipment size and complexity, there are an increasing number of system elements that need to be monitored at the sensors source. Intelligent devices are deployed so that problems can be identified at source.

On the other hand, the manufacturing landscape in developed countries has changed. In the past, a lot of companies are resellers and distributors who will buy and sell products imported for other countries. In recent year, a lot of companies started original equipment manufacturing (OEM) which manufactures key components on behalf of other companies. Some companies will move toward original design and manufacturing (ODM) which design and manufacture their own products. Some companies started to develop their own branding product or original brand manufacturing (OBM).

With shorter product life cycle, companies need to have rapid products introduction and innovation. A lot of the prognostics related products will need to be embedded so that it will be smaller, more compact. Factories and equipment need to run twenty-four hours a day and seven days a week (24X7). Remote maintenance, diagnostics and prognostics services to achieve zero downtime become more important. With reduction in production space, prognostics solutions need to be smaller and compact with more intelligent. 


\section{BACKGROUND}

Early detection of failures in systems is very crucial for maintenance operations. With increasing trend towards automation in different manufacturing industries, it has become necessary that the downtime of any equipment system be reduced to minimum. Machine breakdowns are not only expensive in terms of production losses but also important in meeting production schedules. In addition, due to the fast growth of equipment size and complexity, there are an increasing number of system elements that need to be monitored. Most of the equipment are complicated integrated electro-mechanical and required some embedded devices, sensors to provide prognostics features.

\section{A. Definitions of Manufacturing Prognostics}

Manufacturing prognostics (or Prognostics for manufacturing and engineering) has been interpreted by various researchers. Reference [12] defines prognostics as the ability to "predict and prevent" possible fault or system degradation before failures occur. If we can effectively predict the condition of machines and systems, maintenance actions can be taken ahead of time. As a result, minimum downtime can be achieved. Prognosis has been defined by [13] as "prediction of when a failure may occur” i.e. a means to calculate remaining useful life of an asset. In order to make a good and reliable prognosis it must have good and reliable diagnosis. Manufacturing prognostics is explained as tackling problem by predicting the occurrence of an event through analyzing the trend of the data, preceding this particular event. Manufacturing prognostics improve the overall operations of manufacturing maintenance and provide for competitive advantages. Various connotations of manufacturing prognostics given by other researchers are illustrated in Table 1 below. It is clear that manufacturing prognostics has significant role to play and needs critical attention.

\section{B. Prognosis Representation}

The notation of prognosis has been addressed widely in the literatures by various authors. Prognosis research is done in areas such as, mechanical systems (e.g., rail transport, automotive, and aircraft), power systems (e.g., fossil-fuelled power plants), and continuous-time production processes (e.g. chemical and petrochemical plants, and pulp and paper mills) where structural durability and operational reliability are critical, also prognosis work found to be high in Department of Defence (DOD), including Navy, Air Force, Army and DARPA, is approaching development of prognosis architectures and technologies in different ways [17]. Prognosis results are used for proactive decisions about preventive and/or evasive actions (e.g. CBM, mission reconfiguration) with the economic goal of maximizing the service life of replaceable and serviceable components while minimizing
TABLE 1: DEFINITIONS OF MANUFACTURING PROGNOSTICS

\begin{tabular}{|c|c|}
\hline Author's & Connotations \\
\hline $\begin{array}{l}\text { Brotherton } \\
\text { [3] }\end{array}$ & $\begin{array}{l}\text { Ability to access the current health of a part for a fixed } \\
\text { time horizon or predict the time to failure }\end{array}$ \\
\hline Engel [7] & $\begin{array}{l}\text { Capability to provide early detection of the precursor } \\
\text { and/or incipient fault condition (very "small" fault) of } \\
\text { a component, and to have the technology and means } \\
\text { to manage and predict the progression of this fault } \\
\text { condition to component failure }\end{array}$ \\
\hline $\begin{array}{l}\text { Katipamul, } \\
\text { [11] }\end{array}$ & $\begin{array}{l}\text { Address the use of automated methods to detect and } \\
\text { diagnose degradation of physical system performance, } \\
\text { anticipate future failures, and project the remaining } \\
\text { life of physical systems in acceptable operating state } \\
\text { before faults or unacceptable degradations of } \\
\text { performance occur. }\end{array}$ \\
\hline Lee [12] & $\begin{array}{l}\text { Ability to "predict and prevent" possible fault or } \\
\text { system degradation before failures occur }\end{array}$ \\
\hline Lewis [13] & $\begin{array}{l}\text { Prediction of when a failure may occur. To calculate } \\
\text { remaining useful life of an asset }\end{array}$ \\
\hline Smith [20] & $\begin{array}{l}\text { The capability to provide early detection and isolation } \\
\text { of precursor and/or incipient fault condition to a } \\
\text { component or sub-element failure condition, and to } \\
\text { have the technology and means to manage and predict } \\
\text { the progression of this fault condition to component } \\
\text { failure }\end{array}$ \\
\hline Su [22] & $\begin{array}{l}\text { The identification of incipient faults, is usually } \\
\text { considered and treated as a component/part problem } \\
\text { rather than a system problem }\end{array}$ \\
\hline
\end{tabular}

operational risk [15], as main concept of prognosis is to measure the remaining useful life of a component. There are several factors that are critical to perform a prognosis [18], including

- Current health state

- Historical health state

- $\quad$ Past maintenance history

- Expected usage of the equipment

Prognosis makes use of not only the historical data and available knowledge, but also profiles of future usage and external factors. The early research on prognostics has dealt largely with specific applications or case studies. This is expectedly so, since prognostics as an engineering problem arose from a need to promote condition based maintenance (CBM) practices for reducing costs incurred during inefficient schedule-based preventive maintenance. Currently, there are many prognostics techniques and methods. The prognostics methods can be classified as the following two approaches [14].

- Data-driven: derived pattern recognition theory based on statistical and learning from routinely monitored system operating data.

- Model-based: derived mathematical model based on statistical and outcomes of consistency checks between the sensed measurements of a real system and the outputs of a mathematical model.

Prognostics are receiving most attention for systems consisting of mechanical and structural components, where there is an opportunity to change current maintenance 
practices from scheduled-preventive to condition-based maintenance [15]. A large number of recent industrial research and development efforts in prognostics has been spurred by the military seeking to change its maintenance practices; to a lesser extent, the need for prognostics has also been recognized by other industries. The ability to predict the onset of failure is key to the reduction in maintenance costs, downtime, and health hazards in industrial environments [1].

\section{Prognostics Techniques}

Intelligent techniques, such as expert system, neural network, fuzzy logic and genetic algorithm, have been employed to assist the diagnostic task to correctly interpret the fault data. Neural network technique has gained popularity over other techniques as it is efficient in discovering similarities among large bodies of data.

1) Artificial Neural Networks (ANN): ANN is data processing systems consisting of a number of interconnected processing elements called neurons. The neurons organized in layers which include an input layer, a set of intermediate layers, and an output layer. ANN has found increasing favour in manufacturing systems research because of their ability to perform robustly in noisy environment [2]. ANN-based algorithms are suitable for multiple sensors information as they can represent the nonlinear characteristics of machining process, learning, noisy suppression and parallel computation abilities. They are a type of massively parallel computer architectures based on brain-like information encoding and processing models with learning, association, categorization, generalization, feature extraction and optimization. ANN is like a black box model which accepts inputs, processes them and produces outputs according to some non-linear transfer function [25]. ANN learn solutions from supplied data without specification of rules of a knowledge-based system. Most of the literature concerning fault diagnosis and neural networks has focused on fault detection based with steady state data. Reference [23] applied neural networks for detection and diagnosis of faults in steady state conditions. ANN is massively parallel, extremely fast and intrinsically fault tolerant and can be taught to perform complex tasks without programming. They are able to learn from experience, generalize from examples, and extract essential characteristics from noisy data [9]. It can be implemented in hardware, software or hybrid of both.

2) Fuzzy Logic (FL): FL is a problem-solving control system methodology that lends itself to implementation in systems ranging from simple, small, embedded microcontrollers to large, networked, multi-channel PC or workstation-based data acquisition and control systems. FL provides a simple way to arrive at a definite conclusion based upon vague, ambiguous, imprecise, noisy, or missing input information. FL's approaches problems by mimics how human make decisions, only much faster. Reference [10] explained that FL offers several unique features that make it a particularly good choice for many prognostics related control problems.

Reference [24] presents work describing an automatic diagnosis system for fault classification in rolling bearings based on fuzzy logic analysis. Where fuzzy logic is considered to be a flexible tool which allows the modelling of uncertain and ambiguous data frequently found in real situation, and it also makes possible manipulating different method of signal processing in an intergraded context. Reference [5] presents an on-line fuzzy expert system, called alarm filtering and diagnostic system (AFDS), for the purpose of dynamic alarm filtering, overall plant-wide diagnosis, and alarm prognosis. The main objective of the system is to aid the operator by providing clean alarm pictures and compact information about plant abnormalities.

3) Expert Systems: Expert systems or knowledge based systems are suitable for solving problems usually solved by human specialists. Expert systems have been used since mid 1960s. It was believed that expert performance could by produced by combining the power of computers with the laws of reasoning. The process of building expert systems involves knowledge acquisition, knowledge representation and the verification and validation of prototypes.

An expert system based framework for an Incipient Failure Detection and Predictive Maintenance (FDPM) is presented [4]. The FDPM system is comprised of several expert system related components and databases for use by the mathematical and neural network models which predict deterioration of distribution equipment.

Rule-based expert systems are useful in encapsulating explicit knowledge from experts. Usually, rules are expressed in form; IF condition, THEN consequence. The condition portion of the rule is usually some type of fact while the consequence portion can be outcomes that affect the outside world, test another condition or rule, or even add a new fact to the knowledge base. These rules can be specific domain rules or heuristic rules (rules of thumb) and can be chained together using logical operators [8]. Applications of expert systems can be summarized as follows:

- Diagnosing, interpreting, and monitoring problems

- Choosing among analysis and modelling tools.

- $\quad$ Selecting facilities configurations.

- $\quad$ Planning for predictive maintenance and refurbishment

- Capturing, duplicating, and transferring expertise. 


\section{RESEARCH EXECUTION}

This section identified relevant literature, and then classifying literature in different schemes. The classification of manufacturing prognostics is explained by distribution in journals, origin of research and research focus respectively.

\section{A. Distribution of papers in journals}

Numerous articles dealing with the theory and practice of manufacturing prognostics have been published in various journals. A total of 175 papers have been reviewed. The top two journals that have more focus on manufacturing prognostics are Journal of quality in maintenance engineering (12\%) and International society for optical engineering (8\%). Two conferences that have more focus in the area are Aerospace conference (16\%) and Automatic testing conference (7.4\%).

\section{B. Approach and methodology}

In this part, all papers are classified by origin of research: approach and methodology. The approach is categorized into content and process aspects as shown in table 2. Content-related literature addresses issues of manufacturing prognostics context. The content of manufacturing prognostics refers to the choices and actions. Process- related literature addresses issues on how to form manufacturing prognostics; therefore process aspects include models, framework and architectures. Basically, the focus of the literature is on either on content or on process of manufacturing prognostics.

TABLE 2: APPROACH OF RESEARCH
\begin{tabular}{|l|l|l|}
\hline Focus on & $\#$ & $\mathbf{\%}$ \\
\hline Content & 133 & 76 \\
Process & 42 & 24 \\
Total & $\mathbf{1 7 5}$ & $\mathbf{1 0 0}$ \\
\hline
\end{tabular}

The research methodologies used are divided into five categories which are conceptual, descriptive, empirical, exploratory cross-sectional and exploratory longitudinal. Explanation of the above categories is as follows [6].

- Conceptual: Basic and fundamental concepts of manufacturing prognostics.

- Descriptive: Explanation or description of manufacturing prognostics content or process.

- Empirical: Data for study has been taken from existing database, review, case study, taxonomy or typological approach.

- Exploratory cross-sectional: Objective of study is to become more familiar through survey, in which information is collected at one point in time.

- Exploratory longitudinal: Survey methodology where data collection is done at two or more points over time in the same organization.
Table 3 shows the distribution of various methodologies used by researchers. Among the methodologies, empirical methodology seems to be the most interested methodology.

TABLE 3: DISTRIBUTION OF VARIOUS METHODOLOGIES
\begin{tabular}{|l|c|c|}
\hline Methodology & $\#$ & $\mathbf{\%}$ \\
\hline Descriptive & 78 & 45 \\
Empirical & 70 & 40 \\
Exploratory Cross-sectional & 18 & 10 \\
Conceptual & 07 & 04 \\
Exploratory longitudinal & 02 & 01 \\
Total & $\mathbf{1 7 5}$ & $\mathbf{1 0 0}$ \\
\hline
\end{tabular}

3) Industrial adaptation: In table 4, all articles classified by industrial adaptation based on the various manufacturing methods followed by the industries such as Artificial Neural Networks, Expert systems, Algorithms, Architectures, Embedded systems, Knowledge Base Systems.

TABLE 4: CLASSIFICATION BY INDUSTRIAL ADAPTATION

\begin{tabular}{|l|l|l|l|l|l|l|l|l|l|l|}
\hline Industries & $\mathbf{M}$ & $\mathbf{M}$ & $\mathbf{M}$ & $\mathbf{M}$ & $\mathbf{M}$ & $\mathbf{M}$ & $\mathbf{M}$ & $\mathbf{M}$ & & $\mathbf{T}$ \\
& $\mathbf{1}$ & $\mathbf{3}$ & $\mathbf{2}$ & $\mathbf{4}$ & $\mathbf{5}$ & $\mathbf{6}$ & $\mathbf{7}$ & $\mathbf{8}$ & $\mathbf{T}$ & $\mathbf{0}$ \\
\hline Mechanical systems & 23 & 13 & 8 & 6 & 11 & 6 & 2 & 3 & $\mathbf{7 2}$ & $\mathbf{4 1}$ \\
\hline Electrical Systems & 15 & 9 & 8 & 5 & 4 & 5 & 0 & 0 & $\mathbf{4 6}$ & $\mathbf{2 6}$ \\
\hline $\begin{array}{l}\text { Industrial } \\
\text { Enterprises }\end{array}$ & 12 & 4 & 5 & 1 & 2 & 3 & 2 & 2 & $\mathbf{3 1}$ & $\mathbf{1 8}$ \\
\hline Construction & 2 & 0 & 1 & 2 & 0 & 2 & 0 & 0 & $\mathbf{7}$ & $\mathbf{4}$ \\
\hline Logistics & 5 & 2 & 1 & 2 & 2 & 3 & 1 & 0 & $\mathbf{1 6}$ & $\mathbf{9}$ \\
\hline Medical & 2 & 1 & 0 & 0 & 0 & 0 & 0 & 0 & $\mathbf{3}$ & $\mathbf{2}$ \\
\hline Total (T) & $\mathbf{5 9}$ & $\mathbf{2 9}$ & $\mathbf{2 3}$ & $\mathbf{1 6}$ & $\mathbf{1 9}$ & $\mathbf{1 9}$ & $\mathbf{5}$ & $\mathbf{5}$ & $\mathbf{1 7 5}$ & $\mathbf{1 0 0}$ \\
\hline Percentage (\%) & $\mathbf{3 4}$ & $\mathbf{1 7}$ & $\mathbf{1 3}$ & $\mathbf{9}$ & $\mathbf{1 1}$ & $\mathbf{1 1}$ & $\mathbf{3}$ & $\mathbf{3}$ & $\mathbf{1 0 0}$ & \\
\hline
\end{tabular}

Note: M1- Neural Networks, M2- Fuzzy Systems, M3-Expert systems, M4-Embedded systems, M5- Algorithm, M6- Knowledge base systems, M7- Software program, M8- Architecture.

The industrial applications include

- Mechanical Systems: It includes maintenance activities in Automotive sectors, (e.g. truck maintenance), Avionics, (e.g.: aircraft applications), Rotating Equipments (e.g. Bearings)

- Electrical Systems: Describes maintenance activities in power plants and electric systems in manufacturing industries.

- Industrial enterprises: Maintenance process in various industries such as semiconductor, chemical, continuous-time production process.

- Logistics: It includes details about maintenance activities in shipboard Machinery, and about the navy logistics maintenance.

- Construction: It includes details about the maintenance activities carried out in the construction industries.

- Medical: Includes the application of prognostics in medical field.

\section{SWOT Analysis}

SWOT (Strengths, Weakness, Opportunities, and Threats) analysis helps to understand factors that have 
greatest actual and potential importance for the research works. Table 5 shows the summary of the analysis.

Strengths: From the classification of journals, the strength of previous research can be observed. Firstly, the previous work focused on content related literature (76\%) rather than process related literature (24\%). Hence, the previous research tends to have strengths on manufacturing prognostics context over planning, developing and implementing the prognostics methods. Secondly, the most popular methodology in the manufacturing prognostics research is descriptive (45\%) and empirical (40\%) methodology. Many researchers explored various intelligent methods to convert raw data from into useful information. Some researchers have applied their research to various industrial applications together with other domain experts. Manufacturing maintenance approaches and implementation of prognostics technique attracted multi-discipline expertise team in the arena. Hence, the research in manufacturing prognostics is considered to be stronger in the algorithms development rather than in framework and architecture in the aspect of prognostics method research.

Weaknesses: Much of the existing literature treats the key industrial application independently and lacking of holistic approach to problems. A lot of researchers used PC based research tools like simulation, Labview, Matlab and PC based prototyping solutions. The research algorithms assume unlimited resources and processing power which might be unrealistic for space constraint environment like manufacturing. Most of the research results are in the form of algorithms and will have a long learning curve and long implementation time for real industrial solution. Most of previous research focused on the content based rather than process based therefore practitioners find difficult to implement the concepts. Moreover, there is lacking research in rapid development environment, real time prognostics and collaborative prognostics which handling of multiple failures. Much research needs to validate more in term of real practice. Some approaches could be difficult to implement for all the technologies such as condition based maintenance and fuzzy approaches.

Although a wide spread expectation of manufacturing prognostics research, rapid development and real time prognostics at sensor was not yet developed completely. In case of remote diagnostics, adaptive diagnostic analysis toolset is not there to assist real time diagnostic process. Further, the guidance to sustain the development of a standard solution to the prognostics has not been pointed out clearly.

Opportunities: The weakness of the research creates opportunities in future work. The opportunities are mainly in considering holistic framework for modelling, rapid development methodologies and real time prognostics at sensors source is important for manufacturing prognostics. Considering prognostics in aspects of hardware systems, processing sensors data at source with adaptive embedded device or system on chip is important techniques can help to sent alert at sensors source. There are needs for processbased research in order to guide the manufacturers and practitioners to model, plan, develop and implement the concepts or frameworks in real world manufacturing environment.

The integration of the predictive maintenance strategy with the other business strategies opens new business opportunities to achieve the sustainable competitive space. Prognostics services could be remote services through the internet and is a useful feature for many other systems. Research areas such as remote condition based maintenance (CBM), remote health and usage monitoring (HUM), and real time partitioning of algorithms for embedded prognostics device can be studied in detail.

Threats: The holistic view in manufacturing prognostics takes time and need several aspects to consider. Generally, each and every method in manufacturing prognostics has its own focus industrial domains. In order to achieve the real overall pictures of prognostics, the conflicts interests in each method must be concerned carefully. The study in extracting generic principles and parameters that applied to most prognostics is difficult. Multiple expertises are required in order to have successful outcome.

Additionally, the increased complexity of manufacturing prognostics demands with more sophisticated algorithms, hardware and software. In order to deploy manufacturing prognostics in variety of real industrial environment, researchers need support from many sources like domain experts, cross disciple researchers, manufacturers. Some of the existing system may be a closed system or legacy system with limited information to add more sensors or enhance it with prognostics features. These will make it difficult for the solution to test or implement. Some research on prognostics might still stay in algorithms development, PC based solution and simulation are often made less overall impact and so their competitiveness can be significantly eroded.

The dynamic of the failure occurrence in the manufacturing prognostics make difficult for researchers to capture all scenarios in their research and so it is very difficult for them to make a standard solution for multiple failure occurrences. The competitive space in manufacturing prognostics is also dynamic. It will continue to change as more cross discipline expertises join the research arena. The validity and usability of the techniques 
or tools must be proved carefully.

TABLE 5: SWOT ANALYSIS

\begin{tabular}{|c|c|}
\hline $\begin{array}{l}\text { Strengths } \\
\text { - Various intelligent methods } \\
\text { explored } \\
\text { - Wide range of industrial } \\
\text { applications studied } \\
\text { - Increased research and industrial } \\
\text { interest } \\
\text { - Multi-discipline expertise team }\end{array}$ & $\begin{array}{l}\text { Weaknesses } \\
\text { - No holistic approach to } \\
\text { problems } \\
\text { - Product specific development } \\
\text { environment } \\
\text { - Simulation, LabView, Matlab, } \\
\text { centralised PC-based solution } \\
\text { - Lack of real time device level } \\
\text { solution } \\
\text { - Long learning curve and } \\
\text { implementation time }\end{array}$ \\
\hline $\begin{array}{l}\text { Opportunities } \\
\text { - Holistic modelling and } \\
\text { methodologies } \\
\text { - Rapid software embedded } \\
\text { system development } \\
\text { environment for shorter products } \\
\text { life cycle and fast changing } \\
\text { requirements } \\
\text { - New maintenance service } \\
\text { opportunities }\end{array}$ & $\begin{array}{l}\text { Threats } \\
\text { - Support from manufacturers, } \\
\text { domain experts and end users } \\
\text { required } \\
\text { - Research moving away from the } \\
\text { industries and users } \\
\text { - Closed system and legacy } \\
\text { system }\end{array}$ \\
\hline
\end{tabular}

\section{CONCLUSION AND FUTURE RESEARCH}

Findings from the survey of 175 research papers related to manufacturing prognostics have suggested that there are a lot of interests and potential industrial applications in this area of research. Many researchers focus on specific solution for some domains using PC based simulation, Labview and Matlab. Manufacturing prognostics can be a new maintenance service opportunities which can reduce cost of production, increase equipment utilization and provide innovative prognostics enhancement products in order to compete with countries with low labour cost and production cost. Holistic approach, common methodology, real-time prognostics devices, real time partitioning of algorithms, and rapid implementation environment are potential future research.

\section{REFERENCES}

[1] Borinski J.W., Boyd C.D., Dietz J.A., Duke J.C., Horne M.R., Fiber optic sensors for predictive health monitoring, AUTOTESTCON (Proceedings), pp 250-262, 2001.

[2] Brophy B., Kelly K., Byrne G., AI-based condition monitoring of the drilling process, Journal of Materials Processing Technology, Vol. 124, Number 3, pp. 305-310(6), 2002.

[3] Brotherton T. et al, A testbed for data fusion for engine diagnostics and prognostics, Proceedings of the 2002 IEEE Aerospace Conference, Big Sky MT, 2002.

[4] Butler K.L., An expert system based framework for an incipient failure detection and predictive maintenance system, Intelligent systems applications to power systems, Proceedings, ISAP '96., International Conference, pp 321 - 326, 1996.

[5] Choi S.S., Kang K.S., Kim H.G., Chang S.H., Nuclear science, development of an on-line fuzzy expert system for integrated alarm processing in nuclear power plants, IEEE Transactions on Volume 42, Issue 4, Part 1-2, pp 1406-1418, 1995.
[6] Dangayach, G.S. and Deshmukh, S.G. (2001) 'Manufacturing Strategy: Literature Review and Some Issues', International Journal of Operations and Production Management 21(7): 884-932.

[7] Engel S.J., Gilmartin B.J., Bongort K., Hess A., Prognostics, the real issues involved with predicting life remaining, Aerospace Conference Proceedings, 2000 IEEE Vol. 6, pp 457 - 469, 2000.

[8] Garga A.K., McClintic K.T., Campbell R.L., Yang C.C., Lebold, M.S., Hay, T.A., Byington, C.S., Hybrid reasoning for prognostic learning in CBM systems, Aerospace Conference, IEEE Proceedings, Vol. 6, pp 2957-2969, 2001.

[9] Gebraeel N., Lawley M., Liu R., Parmeshwaran V., Residual life predictions from vibration-based degradation signals: A neural network approach, IEEE Transactions on Industrial Electronics, Vol. 51, No. 3, pp 694-700, 2004.

[10] Kaehler S.D., Fuzzy logic - an introduction, part 2, http://www.seattlerobotics.org/encoder/mar98/fuz/fl_part2.html, 2006.

[11] Katipamula S., Brambley, Methods for Fault Detection, Diagnostics, Prognostics for Building Systems- A Review, Part I, VOLUME 11, NUMBER 1, Journal of HVAC\&R Research, 2005.

[12] Lee J., Smart products and service systems for e-business transformation, 3e Conférence Francophone de MOdélisation et SIMulation "Conception, Analyse et Gestion des Systèmes Industriels » MOSIM’01 - du 25 au 27 avril - Troyes (France), 2004.

[13] Lewis, SA; Edwards, TG; "Smart sensors and system health management tools for avionics and mechanical systems," Digital Avionics Systems Conference, 1997.

[14] Luo B.A., Pattipati K., Qiao L.; Kawamoto M., Chigusa S., An interacting multiple model approach to model-based prognostics, Systems, Man and Cybernetics, IEEE International Conference, Vol 1, pp 189 - 194, 2003.

[15] Mathur A., Cavanaugh K.F., Pattipati K.R., Willett P.K., Galie T.R., Reasoning and modelling systems in diagnosis and prognosis, Proceedings of the SPIE - The International Society for Optical Engineering, Vol. 4389, pp 194-203, 2001.

[16] Mathur A., Data Mining of Aviation Data for Advancing Health Management,

[17] Nasser L., Tryon R., Integration of material-based simulation into prognosis architectures, Aerospace Conference, Proceedings. 2004 IEEE, Vol. 6, pp 3742 - 3747, 2004.

[18] Provan G., An open systems architecture for prognostic inference during condition-based monitoring, Aerospace Conference, Proceedings, IEEE Vol. 7, pp 3157 - 3164, 2003.

[19] Rao, M., Theisen, C., Luxhoj, J.T., Intelligent system for air-traffic control, 5th IEEE International Symposium on Intelligent Control, vol.25-7, pp 859-863, 1990.

[20] Smith A. E., Coit D. W., Liang Y. C., "A Neural Network Approach to Condition Based Maintenance: Case Study of Airport Ground Transportation Vehicles," IMA Journal of Management Mathematics on Maintenance, Replacement and Reliability, April 2003.

[21] Splunter J.V., et al, The pursuit of competitive advantage value manufacturing in Singapore, Manufacturing Sub-committee, Singapore Economic review committee, www.edb.gov.sg, October 182002.

[22] Su L.P., Nolan M., DeMare G., Carey D.R., Prognostic framework, AUTOTESTCON '99. IEEE Systems Readiness Technology Conference, pp 661 - 672, 1999.

[23] Venkatasubramanian V., R. Rengaswamy, K. Yin and S. N. Kavuri, "Review of Process Fault Diagnosis - Part I: Quantitative ModelBased Methods”, Computers and Chemical Engineering, 27(3), 293311, 2003.

[24] Vicente S., Fujimoto R.Y., Padovese L.R., Rolling bearing fault diagnostic system using fuzzy logic, IEEE-International Fuzzy system conference, 2001

[25] Zaknich, A. Neural Networks for Intelligent Signal Processing, Singapore, World Scientific Publishing Co, Singapore (2003) 